\title{
An Interaction Design Method for Creative Conceptual Models' Design
}

\author{
Maria Laura Martinez \\ Escola de Comunicações e Artes \\ Universidade de São Paulo (USP) \\ São Paulo - SP - Brasil \\ ml.martinez@usp.br
}

\begin{abstract}
How to develop creative digital products which really meet the prosumer's needs while promoting a positive user experience? That question has guided this work looking for answers through different disciplinary fields. Born on 2002 as an Engineering $\mathrm{PhD}$ dissertation, since 2003 the method has been improved by teaching it to Communication and Design graduate and undergraduate courses. It also guided some successful interdisciplinary projects. Its main focus is on developing a creative conceptual model that might meet a human need within its context. The resulting method seeks: (1) solutions for the main problems detected in the previous versions; (2) significant ways to represent Design practices; (3) a set of activities that could be developed by people without programming knowledge. The method and its research current state are presented in this work.
\end{abstract}

\section{Author Keywords}

Interaction design; Methods; Theory; Design thinking; Human-centered design.

\section{ACM Classification Keywords}

H.5.2 [User interfaces]: Theory and methods, User-centered design.

\section{INTRODUÇÃO}

A Interação Humano-Computador (IHC) é uma área dinâmica e interdisciplinar. $\mathrm{Na}$ sua história, teria passado por três ondas conceituais [1] que hoje coexistem [11].

Por outro lado, as diferentes visões de pesquisa em IHC podem ser relacionadas com conceitos que estão por trás dessas três ondas, e que vêm da filosofia da ciência (ontologia, epistemologia, metodologia, axiologia e estrutura retórica) e dos paradigmas de pesquisa ("Positivista - Pós Positivista, Construtivista - Interpretativo e Critico - Ideológico) e isso poderia ajudar tanto na adoção de parâmetros semelhantes no processo de revisão de trabalhos científicos quanto no posicionamento das

Permission to make digital or hard copies of all or part of this work for personal or classroom use is granted without fee provided that copies are not made or distributed for profit or commercial advantage and that copies bear this notice and the full citation on the first page. Copyrights for components of this work owned by others than the author(s) must be honored. Abstracting with credit is permitted. To copy otherwise, or republish, to post on servers or to redistribute to lists, requires prior specific permission and/or a fee. Request permissions from permissions@acm.org.

IHC 2017, October 23-27, 2017, Joinville, Brazil

(C) 2017 Copyright is held by the owner/author(s). Publication rights licensed to ACM.

ACM ISBN 978-1-4503-6377-8/17/10 ..\$15.00

https://doi.org/10.1145/3160504.3160560 pesquisas [11]. Além disso, as ondas de IHC não seriam sinônimos para esses paradigmas de pesquisa "já que diferentes paradigmas de pesquisa podem ser subjacentes à mesma onda". Além do mais, Rogers apud [16] chama de "virada" para o Design a "mudança de embasamento teórico do processo de design de uma perspectiva de prescrição para uma de reflexão" [16] ocorrida a partir de meados da primeira década do século XXI. Essa, simultaneamente com outras três "viradas" (embodiment, culture e wild), compõem o período contemporâneo da pesquisa em IHC [16]. Igualmente, [16] faz um paralelismo entre esse conjunto de teorias e abordagens com a chamada "terceira onda" por Bødker [3].

Este é um trabalho que envolve docência e pesquisa. Apresenta um método de design de interação pensado para ser utilizado principalmente por pessoas não técnicas das áreas de Comunicação e Design. Inicialmente desenvolvido como tese de doutorado em Engenharia, vem acompanhando desde 2002, tanto na teoria quanto na prática, mudanças de paradigma nos campo de IHC, de Comunicação e de Design que lhe serviram de reflexão e aperfeiçoamento. $\mathrm{O}$ método não prescreve, mas descreve etapas que devem ser adaptadas à realidade de cada projeto, através da escolha de técnicas. Atualmente o método se situa entre a segunda e a terceira geração de IHC, dependendo das características de cada projeto e das escolhas particulares ao executar suas etapas. Nos últimos anos, vem sendo utilizado para o desenvolvimento de modelos conceituais criativos de produtos Editoriais digitais dentro do ecossistema do livro, conseguindo resultados expressivos.

$\mathrm{O}$ artigo se estrutura conforme segue: buscando embasar conceitualmente o método e sua aplicação, na próxima seção é discutida a atividade do design como projeto e, no item seguinte, a importância crescente do design de interação em áreas não técnicas. A seguir, é apresentado o método, discutindo seus problemas e mostrando sua evolução. Finalmente, são detalhadas suas etapas e são apresentados resultados da sua aplicação.

\section{DESIGN COMO PROJETO}

Metodologias de design surgiram na década de 60 em torno da engenharia mecânica, arquitetura e design industrial, migrando depois para o software. Inicialmente buscando uma abordagem metodológica comum, com o tempo, cada 
área adotou suas próprias definições e dinâmicas para descrever suas práticas [9]. O que as une é a visão do design como projeto.

Houve um crescente interesse da comunidade de IHC em relação à abordagem mais humana do Design. Donald Norman exerceu grande influência neste sentido, introduzindo o Design centrado no humano [30] e o Design emocional [29]. Outros autores, com grande experiência em práticas de design, também influenciaram fortemente esse interesse dos quais se destaca Bill Moggridge [26], fundador da IDEO (famosa empresa de design) e um dos responsáveis por cunhar o termo "Interaction Design". Ainda, [38] aborda a pesquisa em design e suas relações com a pesquisa em IHC e [2] discute intersecções entre métodos da área de desenho industrial e IHC.

\section{Design de interação}

O Design de Interação tem adquirido uma importância crescente dentro da área de IHC. Entre 2011 e 2014, a ACM conduziu um estudo internacional chamado SIGCHI Education Project, que investigou o que estudantes, educadores e profissionais da área consideram ser prioridade de ensino em IHC [7]. O estudo foi realizado utilizando questionário; entrevistas, workshops e um encontro internacional específico. $\mathrm{O}$ questionário de pesquisa foi distribuído entre educadores de IHC do mundo todo. Obteve 616 respostas em inglês, 156 em português brasileiro, $52 \mathrm{em}$ mandarim e 48 em espanhol. A análise das respostas permite distinguir tendências globais daquelas influenciadas pela cultura local. Apesar das diferenças culturais entre países, há bastante consenso entre as respostas mais importantes analisadas por país. Os três principais grupos (americanos, brasileiros e chineses) acreditam que o Design de Interação - entre 114 campos interdisciplinares - é crucial para a educação em IHC. O Design de Interação aparece também entre os paradigmas de design mais importantes dividindo o espaço com o Design Participativo e o Design da Experiência do Usuário [6 p.12][7].

\section{Pesquisando a atividade de Design}

A literatura mostra estudos realizados a fim de investigar a atividade de Design e compreender melhor tanto o agir (processo) quanto a forma de pensar (concepção), utilizados na sua prática $[13,10,15,4]$. A atividade do designer apresenta padrões típicos de pensamento voltados à síntese e à valorização do pensamento intuitivo ou tácito $[9,26,30$, 36], construído através da experiência prática (learning-bydoing) na solução de problemas [26 p.650]. O conhecimento tácito vai além do racional e é encontrado em designers que trabalham há muito tempo lidando com problemas complexos. Seria similar ao "Eureka" de Arquimedes acompanhado do insight de como calcular o volume da coroa do Rei, durante um relaxante banho, ou o insight de Kekulé que o levou a descobrir a estrutura correta da molécula do benzeno, durante o sono. Sem conhecimento teórico não se chegaria a ele, mas esse tipo de insight está além do racional. É como se o cérebro, de repente, vinculasse experiências, sensações e conhecimentos que ficaram esquecidos com outros que estão sendo ruminados há algum tempo, mostrando conexões imprevistas e soluções inesperadas. Esta dinâmica é comum no processo criativo e é favorecida por momentos de relaxamento e descontração. Ainda, o conhecimento tácito estaria relacionado ao chamado "knowing of promissigness", abordado por Hong e Sullivan apud [21]. Stolterman se refere ao pensamento em design como designerly way of thinking [36]. Outro termo comum é design thinking, popularizado por Tim Brown, CEO da IDEO [4].

\section{O modelo de design Double Diamond}

Designers não começam buscando uma solução, mas investigando o problema para poder compreendê-lo em profundidade [30]. Problemas de design são naturalmente complexos - dependem de muitas variáveis de contexto (e.g. técnicas, socioculturais e econômicas) -, e podem mudar durante o projeto. Por essa razão, também são chamados de wiked problems [36]. Para Archer apud [27]

"o problema do design resulta de uma necessidade [...] as pessoas sentem a necessidade de ter, por exemplo, [...] uma maneira diferente de dispor em casa o espaço para as crianças, ou um novo recipiente mais prático para... Estas e muitas outras, são necessidades das quais pode surgir um problema de design. A solução de tais problemas melhora a qualidade da vida". [27]

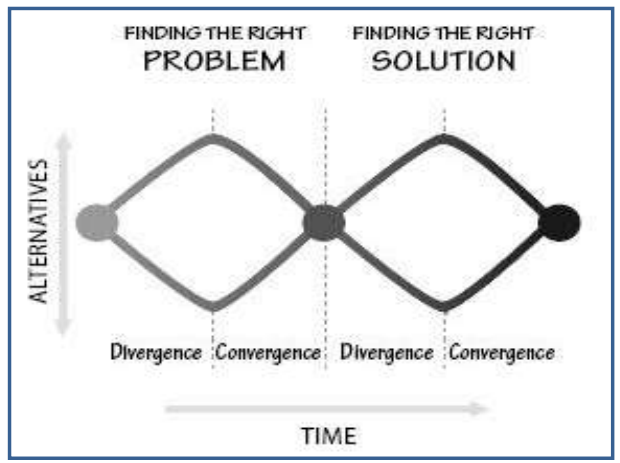

Figura 1 - O modelo Double Diamond de Design. British Design Council apud Norman [30].

A Figura 1 exibe o modelo Double Diamond, proposto em 2005 pelo Conselho Britânico de Design apud [30 cap.6], que representa o processo de design através de dois diamantes (losangos) que ilustram sua abordagem divergente-convergente. No "Espaço do Problema" (primeiro diamante), busca-se compreender profundamente o problema de design dentro de seu contexto. Através da aplicação de diversas técnicas surgem muitos dados e percepções que finalmente convergem para a definição do problema real a ser abordado. No "Espaço da Solução" (segundo diamante), são investigadas muitas soluções distintas, ao mesmo tempo, antes de convergir para a solução final. 


\section{Resistência a abandonar conceitos iniciais}

Curiosamente, alguns estudos detectaram que designers apresentam resistência a abandonar conceitos iniciais e a gerar várias alternativas durante a prototipação (Marples et al. apud [13] e [10 p.203]). Esse resultado entra em conflito com a visão divergente-convergente que seria uma forma típica do design thinking para abordar um problema [30 cap.6]. O processo divergente-convergente potencializa a emergência de soluções disruptivas, e não meramente incrementais [4 p.62-63].

Essa dinâmica de trabalho pode ser observada em equipes criativas, como a da empresa IDEO, em ação ${ }^{1}$. A atividade de design observada em projetos, particularmente dos alunos da disciplina "Design de Interação para Editoração", segue os mesmos padrões dos estudos anteriores [20]. É possível observar em sala a resistência descrita no parágrafo anterior. O vídeo, que documenta a ação da IDEO, é utilizado para exemplificar aos alunos o processo de design abordado na disciplina. Essa estratégia mostrou-se didática e facilitadora do trabalho através do semestre letivo.

\section{O ciclo de vida Estrela}

Particularmente, [15] desenvolve um modelo para representar o ciclo de vida das atividades de design e de desenvolvimento de software. $O$ modelo conecta as diferentes etapas do desenvolvimento a uma atividade central de avaliação de usabilidade e o diagrama resultante se assemelha a uma estrela. O ciclo estrela confere flexibilidade às atividades de design e desenvolvimento: não tem necessariamente um ponto inicial nem uma sequência determinada para as etapas, apenas estabelece que sejam intermediadas por avaliação. Também permite representar tanto abordagens top-down ou bottom-up, quanto as inside-out ou outside-in.

\section{Ondas alternantes de atividades}

Estudos também mostram que designers costumam alternar entre o espaço do problema e o da solução (Esterline et al. apud [13] e [10 p.203, 15 p.97-102]). Igualmente, a atividade de prototipação ajuda tanto a definir e avaliar a solução, quanto, a pensar o problema. Essas ondas alternantes também foram observadas nas atividades de alunos e colegas da autora deste trabalho durante $o$ desenvolvimento de projetos [20].

\section{DESIGN DE INTERAÇÃO E NOVAS MÍDIAS}

Para [12], os programas acadêmicos de novas mídias deveriam alargar seus domínios de conhecimento para incluir o Design de Interação como área central de ensino e aprendizagem. As novas mídias (digitais) mudaram o paradigma da relação com o consumidor, rompendo com a passividade e a imobilidade do receptor, comum nas mídias de consumo em massa, como a televisão. Também

\footnotetext{
${ }^{1}$ Reportagem da TV americana $\mathrm{ABC}$, que mostra a equipe da IDEO trabalhando para resolver um desafio: reprojetar o carrinho de compras de supermercado em apenas cinco dias: https://www.youtube.com/watch? v=QkfC4p0o7Lc
}

influenciam a construção da realidade social e cultural através da difusão de hábitos de consumo, modelos de comportamento e de opinião, entre outros [12, 24]. Disciplinas centradas no humano, em especial o Design de Interação, têm cada vez mais importância no projeto de novas mídias e isso estaria relacionado ao crescente poder do usuário do meio dialógico, digital e conectado. Conforme [32], à medida que as tecnologias online evoluíam, a história do jornalismo online teria passado por três ondas independentes que conferiram ao usuário cada vez mais poder em relação às empresas de Comunicação. A partir de um perfil de consumidor passivo transforma-se em um prossumidor ativo. Igualmente, por meio de ferramentas da web2.0 como blogs, comentários e redes sociais, passa a ter mais voz na internet. Isso gerou uma crescente necessidade de conhecer e atender melhor esse público.

"As empresas que fornecem os melhores salários esperam cada vez mais que os novos especialistas em mídia entendam os fundamentos do bom design, enquanto chegam a soluções de produtos com base em modelagem de experiência do usuário, ao invés de viés pessoal." [12]

Curiosamente, apesar da evidente necessidade, o design tem sido pouco abordado entre as principais teorias das Ciências da Comunicação relacionadas às mídias digitais [24], embora para o filósofo Vilém Flusser, Design e Comunicação sejam duas caras da mesma moeda [14].

Esses fatos abrem oportunidades de cooperação e negócios entre acadêmicos e profissionais de Comunicação, Design e IHC e estimularam o desenvolvimento do método.

\section{Ecossistemas do livro}

Para [17], o livro digital pode ser considerado um exemplo de nova mídia. Desde 2013, a autora vem estudando o design de interação aplicado a produtos Editoriais digitais e interativos, em especial, o livro [21]. O livro digital mais do que um sistema computacional é visto como um elemento de um ecossistema com foco nas pessoas, na cultura e na comunicação. Estes e outros elementos devem ser levados em conta na concepção desses produtos de software. As pessoas interagem com livros digitais dentro de um contexto que inclui, entre outros, sua realidade sociocultural e econômica, seu meio ambiente, experiências passadas e expectativas futuras. Esses elementos e as inter-relações existentes entre todos os componentes desse contexto formam um grande ecossistema no qual se inclui o livro, em todas as suas formas, e sua abordagem estimula o processo criativo e inovador no design de produtos Editoriais digitais. Ecossistemas do livro vêm do livro, podem levar ao livro ou estimulam o surgimento de novos livros, estejam estes em quaisquer formatos: manuscrito, impresso, digital... Essa abordagem não está vinculada a uma única área do conhecimento, pois tem natureza transdisciplinar. São grandes desafios para o Editor: o design de livros digitais enhanced - que incorporam novos conteúdos complementares aos do volume impresso, como vídeo, gravações de áudio ou recursos digitais interativos - 
e, principalmente, aqueles de última geração que utilizam a linguagem do meio digital e conectado, criando novas formas expressivas e mais interativas para o $e$-book que não tem paralelo no impresso. Trata-se de um desafio que exige criatividade e inovação onde a adoção do Design de Interação parece ser uma escolha acertada. $\mathrm{O}$ método descrito, a seguir, vem sendo usado para enfrentar esse desafio em projetos de produtos Editoriais digitais criativos dentro do ecossistema do livro.

\section{O MÉTODO}

Inicialmente é descrito o método desenvolvido em 2002 como tese de doutorado em Engenharia e baseado naquele de Mayhew [25]. Nascido da engenharia de usabilidade, através dos anos o método sofreu forte influencia de resultados de pesquisa e ensino em cursos de graduação e de pós-graduação em áreas de Comunicação e de Design e foi sendo modificado até adotar a forma atual [18, 22, 20, 21], que se aproxima mais ao campo do Design e acolhe o design thinking. Através dos anos, várias versões do método foram avaliadas, experimentadas e observadas, aprendendo com o feedback obtido. Desde 2003, mais de 800 pessoas estiveram envolvidas com a metodologia, participando em projetos como estudantes e/ou colegas de trabalho. Atualmente, o método não é uma versão compacta do original, mas uma versão radicalmente modificada tanto no formato quanto na concepção. A versão atual procura ser suficientemente flexível para acomodar o pensamento tácito e a subjetividade do designer dentro do processo criativo. Essas qualidades se tornaram essenciais para enfrentar problemas de design, naturalmente complexos.

É importante ressaltar que a natureza do método é descritiva e não prescritiva porque não prescreve o que ou como fazer, mas aponta as principais fases que um projeto deve observar. $\mathrm{O}$ caráter descritivo confere ao método o respeito ao conhecimento tácito e à habilidade do designer $\mathrm{e}$ da equipe de design. Busca não tolher a criatividade na dinâmica do projeto, como ocorre com alguns métodos prescritivos. Particularmente, Hong e Sullivan apud [21], elaboram uma pertinente discussão sobre tipos de conhecimento mostrando como ambientes muito estruturados podem inibir o conhecimento tácito e a emergência de saberes.

\section{O método de Mayhew (1999)}

O método de Mayhew [25] aborda todo o ciclo de desenvolvimento: do design à implementação. É fortemente baseado em Engenharia de usabilidade. Há algumas características importantes para compreendê-lo:

(a) O design da interface do usuário é chave. De acordo com Mayhew, os requisitos do usuário e o design da interface do usuário devem direcionar o processo completo de engenharia de software em vez de ser direcionado por ele ou ser incidente a ele.

(b) Níveis de funcionalidades. Não há necessidade de projetar todo o software de uma vez (diferentemente do modelo Waterfall). Suas características podem ser projetadas em camadas. Alguns conjuntos de tarefas (passos ou módulos do método), também permitem refinamento interativo local de uma dada funcionalidade, mediada por avaliações. Essa possibilidade confere flexibilidade ao processo e valioso feedback para a equipe de design.

(c) Distinguindo entre tarefas e técnicas. É possível adaptar a abordagem do ciclo a qualquer projeto pela cuidadosa seleção de técnicas com base em restrições de design. Mayhew descreve cada passo do método como uma tarefa do ciclo de engenharia de usabilidade e cada um tem um objetivo claro para se atingido. Uma técnica é um processo ou método particular para realizar uma tarefa. Cada passo pode ser desenvolvido utilizando uma ou mais técnicas que devem ser selecionadas de forma consistente com o tipo de projeto, contexto e condições de contorno. A correta seleção das técnicas para cada passo/tarefa do ciclo de vida é chave. Projetos pequenos com poucos recursos podem adaptar o método através da seleção de técnicas rápidas e baratas para cada passo. O que distingue um processo rápido de um demorado é a seleção das técnicas. No fim, todos os passos do método devem ter sido executados.

\section{0 método em 2002}

Em 2002 surgiu a primeira versão do método, como tese de doutorado em Engenharia [18]. Foi criado a partir de pesquisa teórica e de experiências práticas fundamentadas no projeto e desenvolvimento e na coordenação de equipes interdisciplinares de desenvolvimento de websites.

É um método descritivo de web design baseado em usabilidade que modifica e especializa para a web o de engenharia de usabilidade de Mayhew [25]. Todas as três características apontadas anteriormente para o de Mayhew são ainda válidas e reutilizadas aqui. No entanto, nesta proposta, dependendo do domínio da aplicação e da sua complexidade, é possível escolher etapas que não serão executadas. Ainda, é possível mixar as etapas e executá-las em ondas alternantes. Desta forma, adota a dinâmica do ciclo Estrela devido à grande flexibilidade que confere ao processo todo e em conformidade com os resultados dos estudos da atividade de design. O método distingue três principais etapas representadas no diagrama da Figura 2, a seguir: o Planejamento, a Implementação e a Distribuição. Todas essas etapas são permeadas e/ou entremeadas por alguma forma de avaliação. No diagrama, os retângulos representam as tarefas do método (também chamadas de módulos). As setas representam a ordem mais provável de execução da sequência de tarefas. A seta horizontal preta e pontilhada, entre as tarefas de "Especificação de conteúdo" e "Implementação", indica um atalho para projetos muito simples. Entre as principais modificações introduzidas sobre o método de Mayhew, pode-se citar:

(1) O método é instanciado para a web, onde é elaborado seu estudo de caso que resultou na Agência Universitária de Notícias online do Departamento de Jornalismo da USP. 
(2) Separa o projeto (chamado de Planejamento) da Implementação. Assim, distingue a fase de design daquela de desenvolvimento. $\mathrm{O}$ método não tem protótipos executáveis na fase do Planejamento, diferentemente ao Nível 2 do método de Mayhew denominado de "Design / testing / development". Aqui há somente protótipos de baixa e média fidelidade.
(3) Especifica a Implementação e a Distribuição antes da etapa de Implementação. Considera que antes da prototipação HTML é relevante Especificar a Implementação e a Distribuição levantando requisitos técnicos e condições importantes para o posterior desenvolvimento. Nesse momento é necessário integrar o conhecimento de administradores de sistemas.

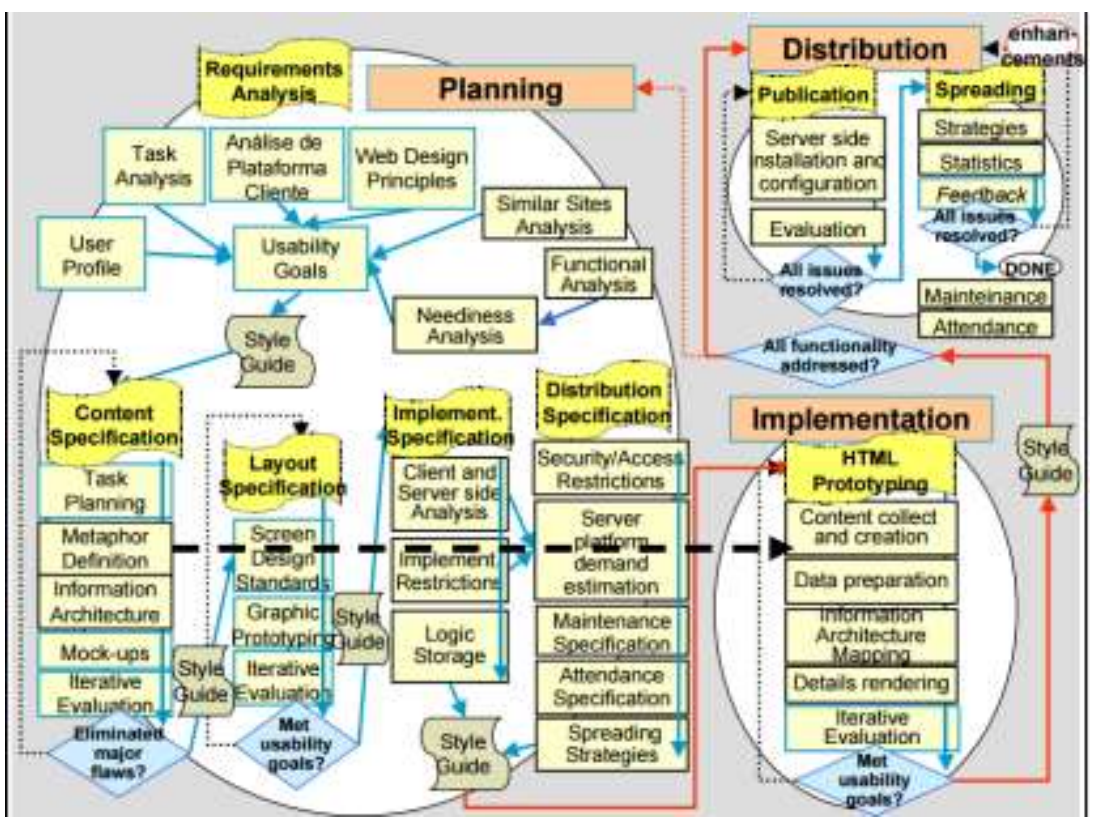

Figura 2 - $O$ método original [18] em 2002.

(4) Incorpora, dentro da Análise de Requisitos, a Análise de aplicações similares e a Análise de funcionalidades e de necessidades. A Análise de aplicações similares é às vezes chamada de análise competitiva e muitas vezes confundida com benchmarking de software concorrente. Seu foco está em identificar, em produtos ou serviços concorrentes, possibilidades tecnológicas e pontos fortes e fracos para o usuário, aprendendo com outras experiências. Por outro lado, a Análise de funcionalidades e necessidades propõe uma reflexão, sobre a experiência e a necessidade humana para as possibilidades da tecnologia, que ajude na elaboração e compreensão do problema. Aqui se elencam possíveis funcionalidades tecnológicas identificando se podem contribuir com as necessidades e objetivos do usuário.

(5) A definição de Metáforas busca a consistência da interface através de escolhas do estilo textual, imagético e sonoro, além do modelo de interação.

(6) A especificação da Arquitetura de informação que, principalmente no caso de sistemas informativos, busca definir e organizar o conteúdo de um site de forma consistente com o modelo mental do usuário. Técnicas como mapas semânticos ou card-sorting podem ser de grande utilidade.

(7). A Especificação da implementação e da distribuição mostrou-se importante para prever e evitar muitos dos problemas do desenvolvimento de web sites. Por exemplo, detalhar como será feita a organização lógica dos arquivos em disco, quais serão as regras para atribuir-lhes nomes e como ela responderá ao crescimento do conteúdo através do tempo (principalmente em sites de notícias). Também, a demanda estimada do sistema servidor, no melhor e no pior caso; a estratégia de marketing a ser adotada no lançamento ou como será feita a manutenção e o atendimento ao público depois de publicado o site.

(8) A Implementação introduz estruturas que ajudam no gerenciamento do desenvolvimento, como a pipeline de implementação, e que permite estabelecer os fluxos de trabalho durante a codificação.

(9) Detalha a fase de distribuição identificando atividades importantes para a divulgação, manutenção e sobrevivência do site.

\section{Discussão: observações e críticas}

Entre as principais observações e críticas feitas ao modelo original pode-se destacar: (1) O grande número de passos que possui, gera desconforto. Alguns relataram a impressão de que o método parece muito complicado com seu monte de "pequenas caixinhas". Análise racional: a queixa é compreensível, e o método é trabalhoso principalmente para novatos dada a falta de domínio e de experiência na seleção de técnicas e de atalhos para adaptar o método à complexidade do problema. À primeira impressão, o 
método parece prescrever todas as tarefas representadas nas "caixinhas" e seu caráter descritivo é ignorado.

(2) O grande volume de dados proveniente de anotações, questionários, vídeos, etc., durante a pesquisa na Análise de Requisitos é difícil de analisar e demanda muito tempo. Por outro lado os dados coletados são, muitas vezes, subutilizados pela equipe de desenvolvimento e pelos próprios designers [34]. Análise racional: embora a diversidade e o volume de dados coletados seja uma ferramenta poderosa para alimentar a percepção e gerar brainstormings produtivos, cheios de insights valiosos, é difícil de organizar e lembrar. Conforme Santos esses dados geram percepções mais valiosas quando compartilhados (idealmente) entre toda a equipe, logo depois de coletados, quando as informações ainda estão frescas na memória [34]. Apesar da utilidade de uma coleta volumosa, uma documentação gorda não se mostra realmente útil no projeto e pode ser minimizada.

(3) Metas iniciais de usabilidade, podem gerar reducionismo - Metas quantitativas de usabilidade são difíceis de ser estabelecidas nos estágios iniciais da análise de requisitos e a escolha parece não cobrir todos os aspectos relevantes do problema. Análise racional: A crítica procede. $\mathrm{O}$ processo de design lida com a complexidade. Estabelecer objetivos mensuráveis em fases iniciais dificulta a exploração de soluções ou a ressignificação do problema após um ciclo de design. A engenharia de usabilidade situada na primeira onda de IHC é fortemente focada em resultados quantificáveis e, para Dix et al., "fornece um meio de satisfazer as especificações de usabilidade e não necessariamente a usabilidade" já que as especificações podem ser estabelecidas de forma errada, principalmente porque nos primeiros estágios do processo de design ainda não se tem informação suficiente $e$ "não é possível definir corretamente metas" [10 p.203].

(4) A Análise de Requisitos parece congelada após o primeiro ciclo - principalmente porque no diagrama possui setas apontando para baixo que a conectam com a Especificação de conteúdo. Essas setas transmitem a falsa impressão de que uma vez estabelecidos, os requisitos não podem ser mudados. Análise racional: Como mostrado pelas observações empíricas de Hix e Hartson [15], e observada nos projetos de alunos e colegas, o designer pode ressignificar o problema após ter prototipado algumas soluções, em um processo de idas e vindas, como em ondas alternantes. A representação do diagrama deve ser repensada.

(5) O método não encoraja soluções divergentes - No diagrama, a sequência iterativa de tarefas foi representada por setas pontilhadas retornando a pontos anteriores no ciclo de vida. Análise racional: A representação transmite a falsa ideia de que as soluções devem ser estudadas uma por vez - e não muitas ao mesmo tempo - em cada ciclo interativo como incentiva $o$ processo convergentedivergente do Modelo Double Diamond de design. É desejável que o método estimule a geração e exploração simultânea de diversas alternativas [30 cap.6]. A representação do método deve ser repensada.

\section{$O$ método em 2017}

Através dos anos, os acertos e fracassos conferiram maturidade à versão atual. A experiência empírica e os conhecimentos construídos no campo de pesquisa permitiram aprimorar a versão inicial introduzindo grandes mudanças que conferem ao método mais leveza e facilidade de aprendizagem. Ainda, o integram melhor com a dinâmica divergente-convergente do modelo DoubleDiamond, que incentiva o processo criativo, e com a flexibilidade do modelo Estrela, que acolhe as ondas alternantes da atividade de Design.

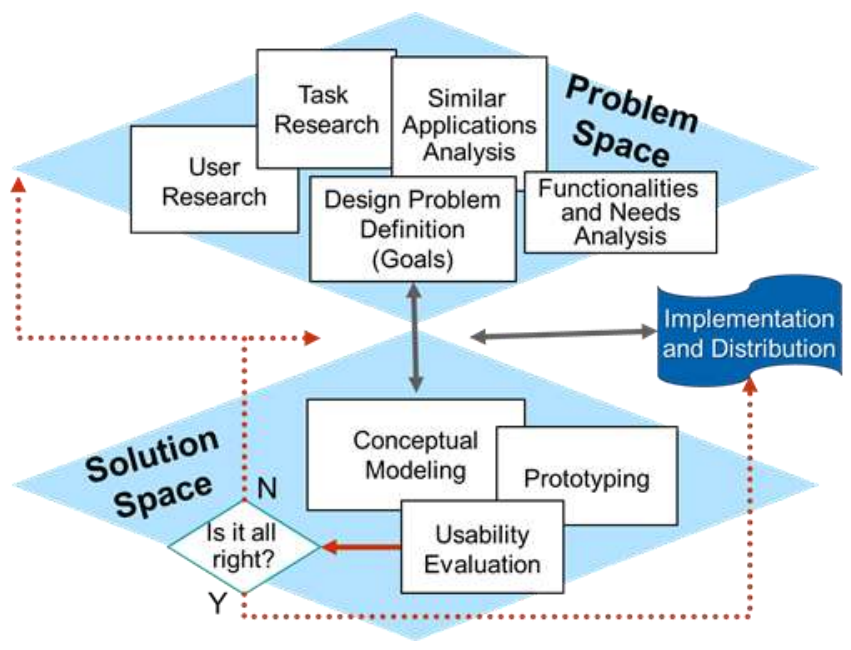

Figura 3 - O método atual.

O método resultante é uma versão bastante modificada da primeira. O diagrama que o representa pode ser observado na Figura 3. As modificações introduzidas no método através do tempo buscaram: (1) Resolver os principais problemas encontrados na proposta anterior; (2) Poder ser empregado por pessoas sem conhecimentos de programação, comuns em equipes de áreas de humanidades e de design, e que cada vez mais se integram às equipes de desenvolvimento; (3) Ser empregado no projeto de interfaces digitais interativas, em geral, além de websites; (4) Formas mais representativas para as práticas que empregam o designerly way of thinking - a condução do projeto deve estimular práticas colaborativas, brainstormings, métodos qualitativos de pesquisa, entre outros.

O diagrama do método manteve as etapas de pesquisa do Usuário e de Tarefas separadas por uma questão didática, no entanto, normalmente são mixadas durante pesquisa contextual (de campo). Preferiu-se a palavra pesquisa a análise, para acolher, além da análise, a experiência holística da síntese, comum à atividade de design e estimulada pela pesquisa qualitativa. Entre suas principais características destaca-se: 
(1) Simplicidade. O diagrama original foi simplificado. Em particular, a etapa "Modelagem Conceitual" engloba atividades que devem se adaptar a uma grande diversidade de projetos. Esse módulo pode comportar atividades como a arquitetura de informação, o webwriting e a definição de metáforas, buscando sintonia e adequação entre humano, contexto e ambiente. Essas atividades serão escolhidas em estreita conexão com a Prototipação e Avaliação e terão maior ou menor ênfase dependendo do escopo do projeto.

(2) Múltiplas camadas de soluções concorrentes. Foi representada a dinâmica divergente-convergente do modelo Double-Diamond através dos dois losangos azuis que servem de fundo da imagem (Figura 3). O trabalho inicial, no espaço do problema, gera uma grande diversidade de dados, percepções e insights antes de convergir para a definição do problema e para a identificação dos atributos de usabilidade e de experiência do usuário mais significativos (Goals). Aqui não são formuladas metas quantitativas de usabilidade. Por outro lado, o espaço da solução deve incentivar a exploração de várias alternativas de modelos conceituais, em paralelo, antes de convergir para o protótipo que se aproxima mais satisfatoriamente à solução do problema. Como apontado anteriormente, a exploração de várias soluções em paralelo encontra resistência nas práticas comuns de design, no entanto, [30 cap.6] defende que favorece o pensamento criativo. Igualmente, uma solução pode emprestar à outra seus melhores insights. Além disso, essa característica, de incentivar o estudo de várias soluções em paralelo, confere ao método um aspecto de múltiplas camadas onde cada solução - cultivada em esboços e protótipos de baixa fidelidade -, é uma camada do método. A solução final vai sendo construída em camadas paralelas nas quais vão se desenhando as ideias do modelo conceitual de forma independente. Essas camadas também podem influenciar umas às outras, misturando-se e aproveitando as melhores ideias de cada uma até convergir para a solução final.

(3) Flexibilidade. A flexibilidade inspirada no modelo Estrela foi representada por setas que apontam nos dois sentidos - para as fases anteriores e posteriores do ciclo. Os designers têm liberdade de movimento entre as etapas do método e entre os espaços do problema e da solução.

(4) Foca o processo criativo. É um método focado no processo criativo. A distinção entre Projeto e Implementação foi mantida. O método é todo voltado para a fase projetual, de Pesquisa e Design, o que permite que seja usado por equipes multidisciplinares formadas por pessoas não técnicas para conceber e gerir a produção do ambiente digital. Esse processo visa à criação de protótipos de baixa ou média fidelidade para comunicar o modelo conceitual concebido com foco no humano dentro do seu ecossistema contextual. O protótipo final, criado na fase convergente do espaço da solução, serve de input (sprint zero) para a implementação.
(5) A implementação necessita da integração entre designers e desenvolvedores. A implementação não é foco do método, mas merece atenção. A fim de implementar o projeto é altamente recomendável a integração do trabalho de designers e de desenvolvedores através de métodos ágeis de engenharia de software [35], onde o usuário final ocupe o lugar do cliente. A versão atual do método foca o projeto do modelo conceitual da interface que é prototipada em baixa ou média fidelidade e testada com usuários reais. Esse projeto é o sprint zero da implementação. Designers devem participar das sessões de avaliação e feedback a cada sprint da etapa de programação. Conforme [5], é importante que os designers acompanhem de perto todas as fases do desenvolvimento para que não se perca o conhecimento e insights adquiridos na pesquisa de design.

\section{APLICANDO O MÉTODO EM 2017}

O método, desde a sua primeira formulação, foi aplicado: (1) no desenvolvimento de uma Agência Universitária de Notícias [22]; (2) por dois projetos vencedores, respectivamente, da Competição de avaliação de Usabilidade organizada pelo Simpósio IHC em 2006 [37] e da Olimpíada USP de Inovação em 2011 [33, 34] e (3) por diversas equipes de alunos de graduação e de pósgraduação para o desenvolvimento de projetos, desde 2003.

Atualmente, o método está sendo ensinado na disciplina de graduação "Design de Interação para Editoração" do curso de Editoração da Escola de Comunicações e Artes da USP introduzida na grade curricular obrigatória em 2013. O foco está no processo criativo e os alunos concebem o modelo conceitual de produtos Editoriais digitais criativos, dentro do ecossistema do livro, que herdam elementos da linguagem de outras mídias e de animações, jogos, redes sociais, crowdsourcing, realidade aumentada, entre outros [20]. Entre 2013 e 2016, foram criados pelos alunos 15 projetos utilizando versões mais recentes do método. Todas essas experiências ajudaram a refletir e aprofundar sobre metodologia de design de interação e a melhorar o método proposto, que continua em aperfeiçoamento. A seguir, são descritas as etapas do método e sua aplicação como compreendidas atualmente.

\section{DESCREVENDO E DISCUTINDO O MÉTODO EM 2017}

1) O espaço do problema. Embora o espaço do problema seja confundido com a Análise de Requisitos da Engenharia, diferencia-se desta. Nesse espaço, a intenção é compreender o problema abordado em profundidade. Para Norman [30] "A brilliant solution to the wrong problem can be worse than no solution at all". Por isso, não se começa um projeto buscando soluções para o problema dado ou pressuposto, mas buscando compreender o assunto em profundidade. Por exemplo, um grupo de alunos, investigou o problema de criar um guia turístico para a cidade de São Paulo e foi além, viu seu vínculo com a cultura e a oportunidade de abordar, por exemplo, detalhes sobre obras de arte do MASP (Museu de Arte de São Paulo) e a biografia dos criadores do museu; também viu seu vínculo 
político e histórico, percebendo que atrás da história oficial de alguns lugares, existe uma história do conhecimento popular, pouco difundida - chamada de crítica por eles - e que seria interessante apresentá-la junto à história oficial, conforme feedback obtido de potenciais prosumidores.

A pesquisa do usuário e de tarefas busca compreender o ser humano dentro do seu contexto e ambiente, procurando embrenhar-se na ecologia da tríade humano-contextoambiente. A preocupação com o contexto é típico da $2^{\mathrm{a}}$ onda de IHC [3], no entanto, aqui a noção de contexto envolve mais do que a inter-relação de características e situações do lugar de interação. O contexto pode abranger variáveis subjetivas, culturais, éticas, ambientais e socioeconômicas, entre outras. Para enfatizar a reflexão sobre as relações entre o humano com o contexto e o meioambiente nos referimos à tríade humano-contexto-ambiente. Entre as principais técnicas empregadas: observações contextuais, entrevistas, questionários, personas e cenários. $\mathrm{O}$ brainstorming permeia praticamente todas as atividades. Embora as técnicas sejam escolhidas e executadas de acordo ao escopo e condições de cada projeto, alguma forma de pesquisa em campo deve ser realizada dado que métodos etnográficos conferem uma visão mais holística do problema. Por outro lado, o estudo de tarefas inicia com o levantamento de objetivos de tarefas. Cooper [8] aborda, de forma prática, as três variáveis do design emocional de Norman - visceral, comportamental e racional - e é interessante introduzir esse recorte teórico para analisar objetivos. Por outro lado, tem se mostrado útil e didático distinguir os objetivos de tarefas típicos (e.g. ao usar um editor de textos normalmente espera-se digitar e editar textos), daqueles críticos. Os objetivos críticos são aqueles que podem causar mais dificuldade ao usuário e que, mesmo assim, são importantes para suas atividades (e.g. usar a ferramenta de macro) ou, ainda, objetivos críticos podem provocar discussões éticas (e.g. copiar/abrir e editar um documento pdf no editor de texto e voltar a salvá-lo em pdf - o texto original é do próprio usuário?). Objetivos típicos são de primeira necessidade em uma aplicação, enquanto críticos merecem atenção especial no projeto e podem agregar valor. No espaço do problema também se investiga o que o usuário atualmente faz para atingir seus objetivos (tarefas). Este não é o momento para apresentar soluções tecnológicas para objetivos/tarefas - isto será feito no espaço da solução.

As análises de aplicações similares e de funcionalidades e necessidades contribuem principalmente para estimular a imaginação e a percepção da equipe com relação a como a tecnologia poderia se integrar no espaço do problema e suas possíveis consequências positivas e negativas.

A definição do problema de design. Os resultados de pesquisa levam a ressignificar o problema inicialmente proposto ou pressuposto aprofundando sua compreensão. Embora conscientes de que não seja possível verbalizar alguns insights e percepções adquiridos, definir o problema é útil - como uma primeira aproximação -, para iniciar o trabalho no espaço da solução. Uma abordagem interessante para definir o problema é aquela adotada pela atividade proposta pela d.School da Universidade de Stanford para exemplificar o processo de design thinking ${ }^{2}$, na qual o problema de design é descrito como segue:

'<user name/description $>$ needs a way to <user's need $>$ because (or "but..." or "Surprisingly") <insight $>$ '

Onde o texto, entre os sinais de menor e maior $(<\mathrm{e}>)$, é variável (notação desta autora). É importante estar ciente de que esta não é uma definição categórica nem permanente. Âs vezes ocorre, no espaço da solução, de perceber que é necessário voltar ao espaço do problema para aprofundar ou reformular a pesquisa como observado na dinâmica comum em aula e também por [30,cap.6].

Embora a abordagem descrita para o espaço do problema pareça pouco técnica e vagamente definida, a experiência através de anos de aplicação mostrou que deixar esse lugar aberto é estratégico para o processo criativo e inovador. Tentar detalhar e formalizar nessa etapa pode inibir a amplitude da exploração e poderá desmotivar uma equipe não técnica. Como o processo de design se dá em ciclos de aperfeiçoamento e através de avaliações formativas, detalhes que escapem à falta de rigor inicial geralmente podem ser detectados e corrigidos mais adiante.

Metas de experiência do usuário (ux) e de usabilidade inspiram e guiam o trabalho no espaço da solução. Como visto nas críticas ao método inicial, há problemas para a abordagem quantitativa da usabilidade nos ciclos iniciais do projeto. Aqui a escolha de metas é apenas qualitativa. Preece et al. [31] utilizam a designação de "Metas" e não a distinguem daquela de "Atributos" como é feito aqui. Essa distinção é feita por compreender que o atributo se transforma em meta apenas quando se faz uma escolha que o qualifica ou quantifica para um determinado projeto. A escolha das metas de ux é precedida de uma reflexão em que a equipe é encorajada a pensar nelas como "sensações" e "experiências" desejáveis que a interface deveria despertar e provocar em seus usuários. Isto leva a selecionar os atributos de ux mais importantes e, a partir dessas escolhas, esses atributos se transformam em metas qualitativas que guiarão a busca de soluções. Para a seleção são utilizados os atributos de ux apresentados em [31]. Por outro lado, para a seleção das metas de usabilidade são utilizados os cinco atributos de Nielsen [28], empregados há longa data em projetos na web, e com os quais temos mais familiaridade. Os atributos são analisados a partir dos achados no espaço do problema e são escolhidos os dois ou três mais importantes, que passam a ser metas qualitativas.

2) No espaço da solução, são investigadas, em paralelo, um conjunto de soluções para o problema de design. O modelo

\footnotetext{
${ }^{2} \mathrm{https} / / / \mathrm{dschool}$.stanford.edu/groups/designresources/wiki/4 dbb2/The_Wallet_Project.html
} 
conceitual vai sendo desenhado através de esboços ([5] distingue esboço de protótipo), que convergem para protótipos de baixa e média fidelidade. Os protótipos são avaliados através de testes de usabilidade com usuários reais. No fim, se obtém um modelo conceitual prototipado em baixa ou média fidelidade e que servirá de sprint zero para o desenvolvimento. Dependendo do tipo de aplicação sendo projetada podem ser escolhidas diferentes abordagens e técnicas para criar o modelo conceitual, como cardsorting - para aplicações informativas -, ou a roda de Black [23] - para transformar narrativas lineares em hipermídia. $\mathrm{O}$ esboço é fundamental como ferramenta de comunicação e feedback rápido na fase divergente. $\mathrm{Se}$, em vez de um produto, for criado um serviço, esboços podem ser substituídos por storyboards ou técnicas teatrais de encenação comuns em atividades de ux design. $\mathrm{O}$ mais importante aqui é o processo criativo na busca de soluções.

A seguir, é exemplificado um recorte de uso através de um projeto desenvolvido por quatro alunas do curso de Editoração, sob supervisão desta autora. Chama a atenção como os resultados da pesquisa aprofundam e despertam a atenção para o problema abordado no espaço da solução. $\mathrm{O}$ projeto "Fábrica de Historinhas" foi pensado para crianças. A ideia inicial era fazer um livro digital interativo com funções didáticas e de entretenimento. Foram necessárias algumas idas e vindas, do espaço do problema para o da solução, para se transformar em um projeto criativo e inovador. A pesquisa constatou que crianças pequenas consomem repetidamente as mesmas histórias clássicas e elaboram sua subjetividade através delas; possuem grande criatividade; gostam de desenhar e de imaginar suas histórias; através dessas histórias expressam valores, medos e sentimentos que geralmente não conseguem verbalizar e possuem um sentimento bastante comum de solidão. Contribui para o sentimento de solidão o estilo de vida moderno onde é comum: pai e mãe trabalharem fora de casa; famílias modernas enxutas com um ou nenhum irmão; famílias dispersas geograficamente, sem a proximidade de parentes ou avôs; ambientes de socialização sendo preteridos pelo uso de eletrônicos e a falta de espaços seguros para brincar e fazer amigos fora de casa. Essas são algumas das percepções que foram sendo tecidas e digeridas aos poucos, nas idas e vindas entre as etapas do método, refinando a compreensão do problema. A pesquisa levou a criar o modelo conceitual não de um livro, mas de uma fábrica de livros onde se encontram os clássicos amados pelas crianças que além de ser lidos podem ser personalizados com fotos dos pequenos. A fábrica também permite criar histórias que atribuam continuidade e fins diferentes para as narrativas clássicas ou, ainda, criar histórias totalmente novas utilizando desenhos, sons e/ou textos. Essas novas histórias, ou aquelas reescritas, podem ser compartilhadas com amigos virtuais sob a supervisão dos pais. Para os pais, as histórias criadas por seus filhos lhes permitem entrar em contato com sua subjetividade, percebendo angústias, gostos e medos - características que às vezes fogem na relação corrida da vida cotidiana. A aplicação tem o potencial de criar diálogos ajudando a lidar com esse sentimento de solidão enquanto apoia a criatividade das crianças para contar histórias. Este é um resumo que exemplifica as possibilidades do método. Igualmente, mostra o potencial de cooperação entre pessoas de humanidades (que já o estão utilizando), e profissionais das áreas de Computação, User Experience e IHC.

\section{CONCLUSÃO}

$\mathrm{O}$ artigo apresenta um método descritivo compreendido como um processo não apriorístico, que se configura através da práxis. Surgiu do trabalho de pesquisa e de docência. Vem sendo aplicado com sucesso no projeto de interfaces para comunicação, informação, cultura e entretenimento. No correr do tempo, foi se especializando para poder ser usado por equipes não técnicas, compostas por pessoas das humanidades, mas não se restringe a esse público. Através dos anos, a experiência empírica, aliada à pesquisa teórica, permitiu aprimorar a versão inicial com grandes mudanças que conferem ao método mais leveza e facilidade de aprendizagem. Ainda, o integram com a dinâmica convergente-divergente do modelo DoubleDiamond, que incentiva o processo criativo e com a flexibilidade do modelo Estrela, que acolhe as ondas alternantes da atividade de design.

\section{AGRADECIMENTOS}

Aos colegas e alunos, pela oportunidade e motivação; ao LSI / EPUSP pela orientação e apoio; à NAP NAWEB, pelo suporte e, aos meus mestres, minha profunda gratidão.

\section{REFERÊNCIAS}

1. J. Bardzell; S. Bardzell 2016. Humanistic HCI. Interactions. Mar-Apr, 2016, 3(2), 20-29. DOI= $10.1145 / 2888576$

2. G. Barros e C. Z. Costa 2010. Aprendendo com o desenho industrial: uma análise de metodologias aplicadas ao design de interação. Anais do 10o. Cong. Internac. de Ergon. e Usabili. de Interf. HumanoComputador (USIHC'10).

3. S. Bødker 2006. When second wave HCI meets third wave challenges. Proc. of the 4th Nordic Conference on Human-Computer Interaction. ACM, New York, 18. DOI $=10.1145 / 1182475$

4. T. Brown 2009. Change by design. Harper Collins, New York, NY.

5. B. Buxton 2007. Sketching user experiences: getting the design right and the right design. Morgan Kaufman, San Francisco, CA.

6. E. F. Churchill; A. Bowser; J. Preece 2012. Report of 2012 SIGCHI Education Activities.

7. E. F. Churchill; A. Bowser; J. Preece 2016. The future of HCI education: a flexible, global, living curriculum. Interactions. Mar-Apr, 2016, 3(2), 70-73. http://dl.acm.org/citation.cfm?id=2888574 
8. A. Cooper; R. Reimann 2007. About face 3: the essentials of interaction design. Wiley Publishing Inc.

9. N. Cross 1993. A history of design methodology. In: Design methodology and relationships with science. NATO ASI Series V.71: 15-27.

10. A. Dix; J.E. Finlay; G.D. Abowd; R. Beale 1997. Human-Computer Interaction (2nd. ed.). Prentice Hall.

11. E. F. Duarte; M.C.C. Baranauskas 2016. Revisiting the three HCI waves: a preliminary discussion. In: Proc. of $X V$ Brazilian Symp. on Human Factors in Comp. Systems (IHC '16). São Paulo, Brazil.

12. A. Fayola; S. B.Davis; R. L. Edwards 2010. Extending knowledge domains for new media education: integrating interaction design theory and methods. New Media \& Society. 12(5) 691-709.

13. S. Finger and J. Dixon 1989. A review of research in mechanical engineering design. Part I: descriptive, prescriptive, and computer-based models of design processes. Reserach in Engin. Design 1,1: 51-67.

14. V. Flusser 2007. O Mundo Codificado. CosacNaify. São Paulo, Brasil.

15. D. Hix; H.R. Hartson 1993. Developing user interfaces: ensuring usability through product and process. New York, NY: John Wiley \& Sons, Inc.

16. G. Kira; L.E. Merkle 2016. Articulating human computer interaction with science, technology and society studies. Proc. of XV Brazilian Symp. on Human Factors in Comp. Systems (IHC '16). Brazil.

17. L. Manovich 2001. The language of new media. Cambridge, Mass.: MIT Press.

18. M.L. Martinez 2002. Um método de webdesign baseado em usabilidade. Ph.D Dissertation 301p. Escola Politéc. Univ. de S.Paulo. São Paulo, SP. Brasil.

19. M.L. Martinez 2014a. Livro digital: continuidades e rupturas de um mercado em transformação. In: XIX Congresso Brasileiro de Ciências da Comunicação na Região Sudeste. Intercom. Vila Velha, ES. Brasil.

20. M.L. Martinez 2015c. Ensinando design de interação no curso de Editoração. In VI Workshop sobre Ensino de IHC (WEIHC). XIV Simp. Bras. de Fat. Humanos em Sist. Comput. Salvador, BA. Brasil. 5-8.

21. M.L. Martinez 2017. Introduzindo o livro digital no curso de Editoração: uma busca epistêmica. Revista de Graduação da USP. Universidade de São Paulo. p.5366. V.2, N.1. Mar/2017. DOI: http://dx.doi.org/10.11606/issn.2525-376X.v2i1p53-66

22. M.L. Martinez et al. 2006. A web design method based on usability applied to an online university news agency. In Proc.of the Brazilian Journ.Conf.(SBPJOR), Porto Alegre, RS. Brasil.

23. M.L. Martinez et.al. 2010. The Black's Wheel: a technique to develop hypermedia narratives. In: Online
Proceedings of the 11th Int. Symp. on Online Journ. (ISOJ'2010) Austin, TX.

24. L.M.S. Martino 2014. Teoria das Mídias Digitais. Editora Vozes. Rio de Janeiro, Brasil.

25. D. Mayhew 1999. The usability engineering life cycle: a practitioner's handbook of user interface design. Morgan Kaufmann, San Francisco, CA.

26. B. Moggridge 2007. Designing interactions. MIT Press, Cambridge, MA.

27. Bruno Munari 1981. Das coisas nascem coisas. Lisboa: Edições 70.

28. J. Nielsen 1993. Usability Engineering. Morgan Kaufmann.

29. D. Norman 2005. Emotional Design: why we love (or hate) everyday things. Basics Books.

30. D. Norman 2013. The design of everyday things: revised and expanded edition. Basic Books, NY.

31. J. Preece; Y. Rogers; H. Sharp 2011. Interaction Design: Beyond Human-Computer Interaction. 3rd. Ed. New York (NY): John Wiley \& Sons.

32. L. Pryor 2002. The third wave of online journalism. Online. JournalismReview. Apr, 182002. http://www.ojr.org/ojr/future/1019174689.php

33. A.S. Rozestraten et al. 2011. Rede social ArquigrafiaBrasil: design de um ambiente online baseado em transdisciplinaridade e colaboração. In Anais do VII Simp. Bras. de Sist. Colab. (CSCW'11). Belo Horizonte, MG, Brasil.

34. A.P.O. Santos 2012. Aplicação de práticas de usabilidade em software livre. MSc Thesis. Instituto de Matemática e Estatística. Universidade de São Paulo, São Paulo, SP, Brasil.

35. T.S. Silva; M. Silveira; Maurer, F. 2014. Best practices for integrating user-centered design and agile software development. XV Brazilian Symp. on Human Factors in Comp. Syst.(IHC '14).43-45.

36. E. Stolterman 2008. The nature of design practice and implications for interaction design research. International Journal of Design 2,1: 55-65.

37. E. Volpato; E. Sobral; L.F.C. Silva; M.L. Martinez 2006. Relatório para a competição de avaliação do sistema JEMS. In: Proc. of VII Brazilian Symp. on Human Factors in Comp. Systems (IHC'06). ACM.

38. J. Zimmerman; J. Forlizzi; S. Evenson. 2007. Research Through Design as a Method for Interaction Design Research in HCI. Proc. of the SIGCHI Conf. on Hum. Fact. in Comp. Syst. (CHI'07). 493-502. 